\title{
Ações antrópicas e exploração dos recursos ambientais no meio rural, no norte do RS: questões históricas, culturais e desafios para projetar novas atitudes
}

\author{
Anthropogenic actions and exploitation of environmental resources in rural areas, in the north of \\ RS: historical and cultural issues and challenges to project new attitudes \\ Acciones antropogénicas y explotación de recursos ambientales en zonas rurales, en el norte de la \\ RS: problemáticas históricas y culturales y desafíos para proyectar nuevas actitudes
}

Recebido: 09/08/2021 | Revisado: 12/08/2021 | Aceito: 12/08/2021 | Publicado: 15/08/2021

\author{
Genesio Mario da Rosa \\ ORCID: https://orcid.org/ 0000-0003-1247-2286 \\ Universidade Federal de Santa Maria, Brasil \\ E-mail: genesiomario@yahoo.com.br \\ Fabiana Regina da Silva \\ ORCID: https://orcid.org/ 0000-0002-3030-238X \\ Universidade Federal de Santa Maria, Brasil \\ E-mail: fabianareginadasilva@yahoo.com.br \\ Jefferson Alves da Costa Júnior \\ ORCID: https://orcid.org/ 0000-0001-7572-3930 \\ Universidade Federal de Santa Maria, Brasil \\ E-mail: dr.jeffersonjunior@gmail.com
}

\begin{abstract}
Resumo
O objetivo deste texto é refletir sobre aspectos históricos, culturais e as ações antrópicas no meio rural na exploração dos recursos ambientais, na região norte do estado do Rio Grande do Sul. Dimensiona sinteticamente, aspectos do perfil de ocupação do território e abandono do extrativismo, pós-colonização e inserção de migrantes europeus no século XX, o estabelecimento das relações de produção e uso dos recursos naturais e impactos gerados pela produção agrícola. Para tanto, se utiliza de fontes bibliográficas, reflexões teóricas e estudo diagnóstico realizado em doze municípios da referida região. Aponta à necessidade da construção de novas perspectivas culturais, políticas públicas, programas de capacitação e de educação ambiental, de modo a desenvolver uma consciência social coletiva capaz de ampliar o uso sustentável dos recursos ambientais, viabilizando o desenvolvimento das propriedades rurais e o fortalecimento das cadeias produtivas.
\end{abstract}

Palavras-chave: Ações antrópicas; Norte do RS; Meio ambiente; Sustentabilidade.

\begin{abstract}
The objective of this text is to reflect on historical, cultural aspects and anthropic actions in rural areas in the exploration of environmental resources, in the northern region of the state of Rio Grande do Sul. post-colonization and insertion of European migrants in the 20th century, the establishment of relations of production and use of natural resources and impacts generated by agricultural production. Therefore, it uses bibliographical sources, theoretical reflections and a diagnostic study carried out in twelve municipalities in the region. It points to the need to build new cultural perspectives, public policies, training programs and environmental education, in order to develop a collective social awareness capable of expanding the sustainable use of environmental resources, enabling the development of rural properties and the strengthening of chains productive.
\end{abstract}

Keywords: Anthropogenic actions; North of RS; Environment; Sustainability.

\section{Resumen}

El objetivo de este texto es reflexionar sobre aspectos históricos, culturales y acciones antrópicas en áreas rurales en la exploración de recursos ambientales, en la región norte del estado de Rio Grande do Sul. Post-colonización e inserción de migrantes europeos en el siglo XX. Siglo, el establecimiento de relaciones de producción y uso de los recursos naturales y los impactos generados por la producción agrícola. Para ello, utiliza fuentes bibliográficas, reflexiones teóricas y un estudio de diagnóstico realizado en doce municipios de la referida región. Señala la necesidad de construir nuevas perspectivas culturales, políticas públicas, programas de capacitación y educación 
ambiental, a fin de desarrollar una conciencia social colectiva capaz de ampliar el uso sostenible de los recursos ambientales, posibilitando el desarrollo de las propiedades rurales y el fortalecimiento de cadenas productivas.

Palabras clave: Acciones antropogénicas; Al norte de RS; Medio ambiente; Sustentabilidad.

\section{Introdução}

O objetivo deste texto é contextualizar historicamente e refletir sobre as ações antrópicas no meio rural da região norte do estado do Rio Grande do Sul, tendo como base, entre outras produções, dados produzidos e publicados por Pietrobelli, et. al. (2018), a partir do estudo diagnóstico realizado em doze municípios da referida região ${ }^{1}$. Assim, o olhar sobre o território mencionado, desvela percepções de que as atividades produtivas do meio rural e a exploração dos recursos naturais têm produzido efeitos no que, costumeiramente, convencionou-se chamar de meio ambiente. Surgem dois caminhos complementares para o raciocínio em relação às ações antrópicas e o processo de exploração dos recursos ambientais dessa região: o primeiro em relação a questões culturais e históricas e, o segundo, em relação ao necessário entendimento em construção, das relações antrópicas com o meio ambiente.

De forma macro, os efeitos mais visíveis estão relacionados aos observados e caracterizados como modificação do relevo e alterações fisiográficas da paisagem Pietrobelli, et. al. (2018). Peloggia (1996) caracteriza estes efeitos como elementos que compõe os fundamentos da geologia do tecnógeno que se detém a estudar as ações diretas ou influenciadas pela atividade humana, além de seus processos específicos, que atuam sobre os próprios depósitos tecnogênicos. Estas ações estão alicerçadas em nosso modelo de desenvolvimento social e econômico, mas também histórico e cultural, desenhando-se a partir de objetivos distintos, no decorrer do processo histórico.

Entre o final do século XIX e início do século XX, no que tange a esta região, há uma quebra com o perfil essencialmente extrativista, a partir da adoção de políticas de ocupação de terras devolutas, colonização e inserção de populações migrantes europeias (poloneses, russos, italianos e alemães) a partir das migrações ditas históricas ${ }^{2}$, situadas nos séculos XIX e XX. A inserção destas populações no território relaciona-se com objetivos econômicos de governo, voltados para a diversificação e ampliação da produção alimentícia nacional, mas também e necessariamente, passa a compor uma diversidade e complexificação das relações e construções culturais, considerando as distintas origens, vivências e contribuições destes migrantes, agora em diálogo com as populações já existentes.

A necessidade de se compreender em uma perspectiva interdisciplinar aspectos do contexto histórico de ocupação, a interferência antrópica e a exploração, pode ser vista como uma questão potencialmente relevante para se pensar estes espaços, suas atuais conformações e as relações estabelecidas, assim, produzindo explicações e compreensões que evidenciem elementos que podem não estar sendo considerados e que poderão se colocar em prejuízo. Ou seja, para além da exploração econômica, estão envolvidas variáveis como a cultura e o perfil sócio-histórico regional. Nestes processos históricos e culturais de transformação da natureza, há que se lembrar do sentido cultural, na perspectiva desenvolvida por Rüsen (2015), empregado nas relações sociais humanas e na produção e construção das vivências e experiências. Rüsen (2014) afirma que a cultura dá ao ser humano a possibilidade de atribuição de sentido para agir no mundo e para a forma como ele age. Então, tais processos resultam de diferentes sentidos colocados na práxis humana, na ação racional humana, em relação à natureza. Uma vez que:

\footnotetext{
${ }^{1}$ Estes dados são de propriedade dos autores e estão publicados em formato de livro - Pietrobelli, et. al. (2018), foram coletados a partir das ações diagnósticas realizadas por nosso grupo de pesquisas - estudo realizado em doze municípios do norte do estado do Rio Grande do Sul, pelo Grupo de Pesquisa Gerenciamento Ambiental e Manejo de Recursos Hídricos - GAMRH, da Universidade Federal de Santa Maria - campus de Frederico Westphalen - RS, através do programa denominado GERA, financiado pelo Ministério da Integração Nacional - MI, durante o período de 2014 à 2018.

${ }^{2}$ Tais imbricações têm sido amplamente apontadas em estudos contemporâneos ligados ao campo da História Ambiental, em produções como àquelas ligadas aos estudos do Programa de Pós-Graduação em História e no Programa de Pós-Graduação Interdisciplinar em Ciências Humanas da Universidade Federal de Santa Catarina, através do Grupo de Pesquisa Laboratório de Imigração, Migração e História Ambiental (LABIMHA), entre outros.
} 
A cultura é a resposta que os seres humanos atuantes e sofredores dão a si próprios ao lidarem com a natureza, com o seu próprio mundo social e consigo mesmos e com os outros seres humanos, quando perguntam pelo sentido de sua vida e querem organizá-la de um modo que faça sentido. O sentido determina como as experiências são feitas, como o que se experimenta é interpretado e como as interpretações são empregadas para orientar a práxis vital e motivar à vontade. A cultura se manifesta no cosmo dos símbolos que transformam a natureza em mundo humano (RÜSEN, 2014).

Com diferentes bagagens culturais, compreendemos, reagimos e agimos de diferentes formas nas relações a partir da atribuição de sentidos, estranhamentos e confrontos, diálogo e hibridização. Para Bauman (2012), a cultura só pode existir como crítica prática e intelectual da realidade social existente, como práxis. Esta crítica é capaz de produzir novos olhares e atitudes, e, assim, as ações sociais não são pautadas em definições estáticas.

Neste sentido, retomando o processo histórico, Silva (2014) aponta para a ocupação em perspectiva de colonização dessa região - constituindo as chamadas colônias novas, na segunda fase de colonização do estado do RS, durante a primeira metade do século XX, em contraposição às colônias velhas, loteadas e colonizadas na primeira fase, ainda no século XIX. O perfil de colonização da região insere distintos aspectos étnicos e culturais das populações migrantes, em diálogo com as populações existentes, os ditos nacionais e os indígenas e, desenha um modelo de exploração.

Este modelo que rompe com o extrativismo de erva-mate, por exemplo, na proposta da regeneração natural dos recursos naturais, e insere atividades de produção diversificada de alimentos, através da produção agropastoril em pequenas propriedades que possuem em média, de 20 a 25 hectares, formando colchas de retalhos de produção, com culturas variadas, inseridas a partir de uma significativa mudança cultural e de projeto econômico governamental que promovia os migrantes ao patamar de "mais trabalhadores e produtivos" e desprezava a população local ${ }^{3}$, onde sua cultura e forma de lidar com o meio são vistas como "atrasadas".

Mesmo com a inserção gradual de novas formas de cultivo e aparatos de mecanização, há questões específicas do perfil cultural, vocação regional e relevo, que traçam limites. Assim, essa região foi isolada economicamente a partir da década de sessenta por uma proposta de produção extensiva, por meio da monocultura, incentivada nas outras regiões do estado. O citado isolamento está muito ligado, entre outras questões, a cultura regional, a sucessão familiar - culturalmente as terras da família eram repassadas aos filhos homens, propostas de produção diversificada e, morfologia desta região que apresenta relevo ondulado, assim, inadequado ao cultivo de lavouras em grandes áreas (EMBRAPA, 2013).

Nesta abordagem, ressalta-se a contextualização do meio, pois como muito bem defendeu Hartshorne (1978) $o$ conceito de meio não tem sentido, exceto em referência àquilo que ele envolve. Por outro lado, para Geraldino (2014) o ambiente relativo aos seres inanimados, não vivos ou inorgânicos, age sobre eles deteriorando-os, ou seja, incide sobre eles como uma força externa e contrária. No entanto, para Lewontin (1998) um ambiente é algo que envolve ou cerca, mas para haver envolvimento é preciso que haja algo no centro para ser envolvido. Nessa lógica, o meio ambiente só aflora, indubitavelmente, e em todo o seu sentido quando dispomos do recorte da vida (Geraldino, 2014) como sendo aquilo que por ele é envolvido.

O ser humano, nesta abordagem, vive em profunda dicotomia, pois o analisa colocando-se como um ser à parte dele. Segundo Reigota (2017), esse distanciamento da humanidade em relação á natureza fundamenta as ações humanas tidas como racionais, mas cujas graves consequências exigem respostas pedagógicas e políticas concretas para acabar com o predomínio do antropocentrismo (argumento de que o ser humano é o ser vivo mais importante do universo e que todos os outros seres vivos têm como única finalidade servi-lo). Para isso, é preciso uma compreensão integral, holística, reconstruída, refundada na

\footnotetext{
${ }^{3}$ No início do século XX as populações indígenas da região, assim como em outras regiões brasileiras, foram aldeados. Já os nacionais (descendentes de escravos, fronteiriços), impossibilitados de adquirir terras, uma vez que a política de colonização privilegiava os migrantes, passaram a trabalhar como peões na produção agrícola e de gado.
} 
teoria e, na prática e de análise da relação direta e dependente do homem com o meio, não descolado de processos culturais e históricos de inserção humana, transformação da natureza e produção da vida.

\section{Metodologia}

O presente estudo é essencialmente baseado na legislação pertinente e em referências bibliográficas e teóricas relacionadas ao tema, destacando, entre estas, o já referido trabalho publicado por Pietrobelli, et. al., (2018), a partir do estudo realizado ${ }^{4}$ em doze municípios do norte do estado do Rio Grande do Sul, pelo Grupo de Pesquisa Gerenciamento Ambiental e Manejo de Recurso Hídrico - GAMRH, da Universidade Federal de Santa Maria - campus de Frederico Westphalen - RS, através do programa denominado GERA, financiado pelo Ministério da Integração Nacional - MI. As imagens utilizadas pelos autores neste texto são frutos de um acervo de pesquisa, coletados na pesquisa citada que compõe referida publicação.

A revisão bibliográfica organizou-se a partir da definição das temáticas, imbricações e descritores, entre eles: Meio Ambiente, Ações antrópicas, exploração dos recursos ambientais no Norte do RS, História Ambiental no Norte do RS, ocupação populacional no Norte do RS, Educação Ambiental e Sustentabilidade, no decorrer do segundo semestre do ano de 2020. Assim, realizou-se a seleção de leituras de estudos científicos como artigos, livros, legislação e relatórios técnicos. Essa atitude de pesquisa visou recolher informações e conhecimentos prévios sobre o tema a respeito do qual se procura uma resposta (Gil, 2008) e, consequentemente, estabelecer suas relações.

O texto utiliza-se de uma abordagem qualitativa sobre o objeto, ou seja, busca refletir sobre as questões acima delimitadas, articulando bases empíricas, conceitos e reflexões teóricas e intersubjetivas, conduzindo a interfaces e possibilidades na temática e abordagem, como contribuição de análise reflexiva, fundamentadas nas contribuições de Minayo (2002), que afirma que a pesquisa qualitativa abrange a capacidade de responder a questões particulares. Assim, podendo trabalhar com sentidos e significados, crenças, atitudes, valores, aspirações e motivações, adentrando nos campos dos processos, relações e fenômenos que não podem ser medidos de maneira quantificável e através de variáveis.

\section{Resultados e Discussão}

\subsection{Questões históricas e culturais, econômicas e ambientais no norte do estado do RS}

Atualmente, na região norte do estado do Rio Grande do Sul, com raras exceções, no caso de algumas propriedades maiores, os municípios têm sua atividade econômica essencialmente alicerçada na atividade primária e, consequentemente, na geração de renda (IBGE, 2010). O que torna a receita dos produtores rurais e, consequentemente dos municípios, totalmente dependente das condições climáticas que afetam diretamente a produção agrícola e de proteína animal. Ainda, a comercialização dos produtos, sendo na sua maioria perecíveis, ou seja, de consumo imediato ou que precisam de beneficiamento imediato, e que não encontram estruturas propícias de beneficiamento e nem de industrialização na região (Pietrobelli, et. al., 2018).

Apresentam-se aí, fatores limitantes para a agregação de valor e, consequentemente, sem aumento na renda, fazendo com que a região passe a ser caracterizada como exportadora de matéria-prima bruta. Isto decorre da inexistência de um planejamento regional para as atividades do setor (Pietrobelli, et. al., 2018), existindo, de certa forma, apenas um zoneamento agrícola que define por fatores climáticos, as melhores épocas de semeadura das principais culturas agrícolas desta região. Esta dinâmica vem ainda do período colonizatório, diferente de algumas regiões de colonização brasileiras, que desde o início passaram a organizar-se em cooperativas e grupos produtivos.

\footnotetext{
${ }^{4}$ Os autores do presente texto fazem parte do referido Grupo de Pesquisa e participaram da coleta de dados e organização da obra Pietrobelli, et. al., (2018).
} 
O modelo produtivo atual, segundo Aumond (1999), se baseia na ideia de que o progresso econômico pode ser ilimitado, mostrando-se, na prática, falho. Na visão do autor, o desenvolvimento econômico pode ser factível desde que seja radicalmente alterada a visão política, social e cultural sobre o uso dos recursos naturais. Junges (2004, p. 55) afirma que "as consequências negativas não são fruto da própria ciência e técnica, mas da falta de uma cultura mais sistêmica do ambiente e de um igualitarismo em relação aos seres viventes presentes nas civilizações rurais".

A lógica da região norte do estado do Rio Grande do Sul é inversa à observação de Aumond (1999) e, por outro lado, concorda com Junges (2004), uma vez que, à produção agrícola e de proteína animal em áreas que a legislação não recomenda sua prática, pois, é caracterizada por um relevo fortemente ondulado (EMBRAPA, 2013), recortado por uma abundante malha hídrica, a qual compõe a bacia do Rio Uruguai, o que resulta no uso das encostas para as atividades agrícolas, áreas estas, que ficam propensas à degradação do solo pela erosão e arraste superficial da matéria orgânica, fertilizantes e do próprio solo em razão da declividade do relevo.

O fato de se ter esta abundante malha hídrica foi visto como interessante pelos colonizadores, para suas práticas agrícola e pecuária, porém, um século depois, o prejuízo ambiental devido à falta de consciência ambiental nas ações antrópicas, anuncia a necessidade de urgência em compreender o processo histórico de constituição da região, desenvolver novas perspectivas culturais, repensar as maneiras de produção e exploração econômica, o uso dos recursos naturais, interfaces e estratégias. Neste sentido, algumas ações ainda pouco abrangentes, tem se apresentado nos últimos anos. Em razão dessa grande disponibilidade hídrica existe um esforço de agências de extensão rural como Emater/Ascar e Secretarias de Agricultura dos municípios, etc., para implementar uma maior diversificação de atividades geradoras de renda nas propriedades rurais e, por outro lado, fazer o uso sustentável do recurso hídrico, entre as estratégias, essas instituições têm instigado à produção de pescado.

No entanto, pode-se afirmar que a atividade ainda é tímida e se caracteriza como artesanal, pois não possui efetivo planejamento estratégico por parte dos produtores e gestores municipais, tanto no sistema de produção, industrialização e no processo de comercialização (Pietrobelli, et. al., 2018).

Quando se destaca e dá ênfase ao planejamento da produção, a necessidade de se ter estratégias, não é por mero acaso, visto que o planejamento é considerado a ferramenta básica para o desenvolvimento dos territórios e, como força de lei, para tanto, haveria a necessidade da elaboração de um Plano Diretor, o que passou a ser obrigatório a partir da Constituição de 1988 para as cidades com mais de 20 mil habitantes (Brasil, 1988). No entanto, foi com o Estatuto da Cidade, em 2001, que o meio rural passou a ser considerado no planejamento dos municípios, tendo o Plano Diretor como principal instrumento para o seu ordenamento (Mesquita \& Ferreira, 2017).

A questão abordada acima fica clara quando se observa a descrição do $\S 2^{\circ}$ do artigo 40 que estabelece que o Plano Diretor deverá englobar o território do município na totalidade (Brasil, 2001). Assim, o Plano Diretor deve abranger tanto a zona urbana quanto a zona rural do município. Fica mais claro ainda a abrangência territorial do Plano Diretor quando se observa o inciso VII do artigo $2^{\circ}$ do Estatuto da Cidade onde se lê: integração e a complementaridade entre atividades urbanas e rurais, tendo em vista o desenvolvimento socioeconômico do Município e do território sob sua área de influência (Brasil, 2001).

Dessa forma, ao elaborar e aprovar o Plano Diretor, este deve legislar também as áreas rurais municipais, fato que representaria um avanço na ocupação e no uso múltiplo do solo. Conforme Avelar e Paschoal (2012):

Para garantir o desenvolvimento sustentável das cidades é preciso atentar para a recuperação ambiental, ou seja, devolver ao ambiente suas características originais, a estabilidade e o equilíbrio no ambiente degradado. A qualidade de vida de toda comunidade depende de regulamentação e normas jurídicas protetoras do meio ambiente. $\mathrm{O}$ instrumento jurídico mais importante para a vida das cidades é o Plano Diretor, pois é dele que se originam todas as 
diretrizes e normativas para o desenvolvimento sustentável local. Como cada município possui características socioeconômicas, geográficas e políticas diferenciadas, embora haja um conteúdo mínimo que deve ser englobado, o Plano de cada Município deve ser elaborado de acordo com suas características específicas, estabelecendo as diretrizes básicas para sua política de desenvolvimento e expansão urbana.

Este documento ampara o fato de cada município possui características diferenciadas e estas se relacionam também com o perfil de ocupação das regiões e seus processos históricos e culturais, que são distintos. No entanto, nos municípios abrangidos neste estudo, essa ferramenta estratégica - Plano Diretor, não foi observada. Nem mesmo nos municípios que se enquadram nos critérios de obrigatoriedade de elaboração.

Ressalta-se aqui a importância de políticas públicas e possibilidades de conscientização sobre as ações antrópicas e uso dos recursos naturais, voltadas à construção de novas maneiras de vida. Assim como deve acontecer com os empresários de outras atividades econômicas, aos produtores rurais também cabe o monitoramento da complexidade do ambiente em que estão inseridos, assim, tendo visão sistêmica da atividade desenvolvida, preocupando-se com a elaboração de estratégias para se defender das ameaças e aproveitar as oportunidades (Padilha et. al., 2010).

Além disso, a capacidade gestora do empresário/produtor rural pode ser considerada determinante nos resultados da propriedade. Dessa forma, a inexistência de um plano regional reforça o ato de negligência por parte dos proprietários rurais em relação ao planejamento administrativo, com estratégias, delineamento de objetivos, metas e ações de médio e longo prazo para as propriedades rurais.

Fica claro que a dependência dos fatores de clima, a perecibilidade dos produtos, o ciclo das culturas e criações, além, da possibilidade de incidência de pragas e doenças, leva os produtores rurais a deduzirem que como são fatores na sua maioria, incontroláveis, assim, o planejamento e a consequente avaliação dos riscos se tornam desnecessários. Como consequência, há falta de interesse pelo planejamento e controle das operações, o que expõe o produtor às incertezas do mercado e, por outro lado, o impele ao uso dos recursos naturais de forma desordenada, exploratória e com característica predatória, tomando o caminho inverso ao conceito de sustentabilidade.

Neste ponto, cabe uma nova reflexão em relação às dimensões culturais e a necessidade que as culturas produzidas nas relações sociais e humanas e com a natureza, de fato sejam um continuum, e venham a ser exploradas em proveito de melhores condições de vida no planeta. Conforme afirma Gould (2006): “As sociedades humanas mudam por evolução cultural, e não como resultado de alterações biológicas. [...] A evolução biológica (Darwiniana) continua em nossa espécie, mas seu ritmo, comparado com a evolução cultural, é tão desmensuradamente lento que sua influência sobre a história do Homo sapiens foi muito pequena".

Porém, se aliarmos esse pensamento com o processo de formação da região em estudo, tanto nos aspectos históricos, políticos, étnicos e culturais, já mencionados anteriormente, definidos por perfis de migrantes principalmente ligados ao campo, alguns advindos das glebas na Europa e outros das antigas colônias, somando-se aos nacionais e indígenas ligados às práticas extrativistas de madeira e erva-mate, lembrando ainda, que esta foi uma das últimas regiões do estado a ser colonizada, e que neste período a terra havia se tornado alvo de exploração mercadológica e a colonização voltava-se para a diversificação e ampliação da produção e desenvolvimento econômico, questões estas, que conforme Silva (2019) ultrapassavam os interesses de povoamento dos ditos vazios demográficos em regiões fronteiriças, podemos perceber que estes fatores favoreceram a colonização em pequenas propriedades (SILVA, 2014), observação essa, referendada por Pietrobelli, et. al. (2018), ressaltando que a maioria das prioridades tem área inferior a 20 hectares, e produziram aspectos culturais particulares que ainda são reproduzidos, conforme discutimos acima.

Os fatores anteriormente mencionados, dentre eles os aspectos históricos, são condicionantes de perfis culturais e de exploração dos recursos naturais. Para Silva (2019), as mudanças culturais se constroem de forma significativa nas trocas com 
o diferente, nos estranhamentos e complexificações, nos processos dados em agregar representações e significados. Porém, a referida região mantém um perfil mais isolado e peculiar, de sucessão familiar, iniciado no início do século XX, com a afirmação de preconceitos para com o diferente, entre outros, inserindo-se na narrativa e ótica de que indígenas e nacionais são vistos como atrasados.

Contribui para isso, a distância dos centros urbanos maiores e a falta de políticas públicas e compreensões educacionais escolares ou não, capazes de impulsionar a perspectiva da complexidade na relação com o meio e a interculturalidade, assim como, da necessidade de acompanhamento técnico especializado na organização da produção e do manuseio dos recursos, compreendendo e considerando as características geográficas do relevo e do clima da região. Assim, surgem dois caminhos complementares para o raciocínio em relação às ações antrópicas e o processo de exploração dos recursos ambientais dessa região: o primeiro em relação a questões culturais e históricas e, o segundo, em relação ao necessário entendimento em construção, das relações antrópicas com o meio ambiente.

A primeira delas, histórica e cultural, pode ser definida como sendo resultante, somados os fatores da dinâmica do perfil da colonização e da formação social e étnica, mas também, da educação formal e do acesso a bens e recursos culturais e diálogos interculturais. Isso tudo, retomando a compreensão de cultura e seu papel, abordada na introdução, a partir de Rüsen (2014), e no entendimento de que a História, o passado não está morto, ele é presente, portanto, não pode ser desconsiderado.

Conforme os dados do Atlas de desenvolvimento no Brasil Humano (IBGE, 2010) e, especificamente analisando os dados do Rio Grande do Sul, observa-se que o Índice de Desenvolvimento Humano dos Municípios (IDHM) é 0,746, o que situa essa Unidade Federativa (UF) na faixa de Desenvolvimento Humano Alto (IDHM entre 0,700 e 0,799). Sendo que, a dimensão que mais contribuiu para o IDHM desta Unidade Federativa (UF) foi a Longevidade, com índice de 0,840, seguida da Renda, com índice de 0,769 e da Educação, com índice de 0,642.

No entanto, quando se analisa o quesito educação, observa-se o percentual de 43,79\% para indivíduos com idade de 18 a 20 anos que apresentam ensino médio completo, em contraposição aos 56,21 \% com ensino fundamental completo $\left(1^{\circ}\right.$ ao $9^{\circ}$ ano), para a mesma faixa etária. Essa realidade também foi observada por Pietrobelli, et. al. (2018), sendo que, nos municípios analisados pelos autores, não foi observada a indicação de analfabetos entre os residentes nas propriedades rurais e que $57,69 \%$ dos residentes apresentavam escolaridade de ensino fundamental, em contraposição aos $42,31 \%$ que apresentaram nível médio completo.

Essas pontuações, analisadas à luz do que diz Gould (2006), e as questões já apontadas acima, induzem a reprodução contínua dos modelos sociais e culturais, pois, o acesso às tecnologias e a educação formal e técnica, se considerarmos que o ensino médio pode ser entendido como qualificação técnica, em última análise, dificulta o acesso e, por outro lado, o próprio entendimento das relações antrópicas com o ambiente, trabalhada a partir de uma matriz curricular, por vezes, sistematizada em estratégias curriculares fragmentárias, ou que não atendem ao que orientam documentos como os Parâmetros Curriculares Nacionais $\left(\mathrm{PCNs}^{5}\right)$ e temáticas transversais.

\footnotetext{
${ }^{5}$ Destacamos a Lei Federal no 9.795, de 27 de abril de 1999, que instituiu a Política Nacional de Educação Ambiental, Programa Nacional de Educação Ambiental (PRONEA), bem como: em 1997 os Parâmetros Curriculares Nacionais (PCNs), quando um novo impulso foi dado à Educação Ambiental no Brasil, mais especificamente no ensino escolar. Embora alguns estudiosos questionem o fato de que a Educação Ambiental não tenha se tornado uma disciplina, os PCNs justificam esse fato apontando que a Educação Ambiental será mais bem trabalhada como um tema transversal, estando no âmbito de todas as disciplinas, o que permitirá seu enfoque global e interdisciplinar (BRASIL, 1997), possibilitando a construção da cidadania - conforme preconizada pela Lei de Diretrizes e Bases da Educação Nacional (Lei n ${ }^{\circ}$ 9.394, de 20 de dezembro de 1996). Os PCNs de número nove são dedicados especificamente ao tema "Meio Ambiente e Saúde" (AGUIAR et al. 2017, p. 124). Também merecem destaque as Diretrizes Curriculares Nacionais (DCNs) para a Educação Ambiental, por meio da Resolução $\mathrm{CNE} / \mathrm{MEC} \mathrm{n}^{\circ} 02$ de 15/06/2012. Este documento está atrelado a uma perspectiva que em alguma medida situa- se mais aproximada ao pensamento complexo de Morin, com caráter interdisciplinar e de temáticas transversais na Educação Ambiental, conforme afirma em seu Art. $8^{\circ}$ : de que "A Educação Ambiental, respeitando a autonomia da dinâmica escolar e acadêmica, deve ser desenvolvida como uma prática educativa integrada e interdisciplinar, contínua e permanente em todas as fases, etapas, níveis e modalidades”.
} 
Tudo isso colabora pelo não desenvolvimento de maneira interdisciplinar e complexa e de uma visão ampliada dos valores culturais e do comportamento social ético em relação ao meio ambiente. Fato este, antagônico ou politicamente equivocado, pois o fator educação é um dos que mais contribuiu para a elevação do IDHM da região, apresentando uma evolução de 12,35\% e crescimento de 0,137 em termos absolutos em relação ao ano de 2000 (IBGE 2010).

Ao analisar a presença de educação escolar e universitária e pensá-la com aspectos curriculares e da sua prática pedagógica mais propensa a pensar a região e as dimensões aqui discutidas, pode-se citar formações universitárias, entre outros cursos, a graduação em Engenharia Ambiental, Engenharia Florestal e Agronomia, ligadas ao campus da Universidade Federal de Santa Maria - UFSM, em Frederico Westphalen - RS, o curso de graduação em Tecnologia em Agropecuária, da Universidade Regional Integrada do Alto Uruguai e das Missões - URI/campus Frederico Westphalen, o curso Técnico Agrícola, oferecido pelo Instituto Federal Farroupilha - IFFAR - Frederico Westphalen, e, pela Escola Estadual Celeste Gobatto de Palmeira das Missões - RS e, a formação aliada à Pedagogia da Alternância (Ensino Médio) desenvolvida pela Casa Familiar Rural, ligada à URI - Frederico Westphalen. Porém, embora possa se perceber a presença de ações efetivas em ensino, pesquisa e extensão, ainda são iniciativas bastante recentes (aproximadamente 15 anos) e que atingem um público restrito, em se pensando no aspecto da mudança cultural.

Infere-se que, embora a educação formal seja a melhor perspectiva para se pensar mudanças de atitude em relação às questões ambientais, a ainda escassa qualificação formal e as fraturas curriculares e epistemológicas na educação básica, técnica e superior, reduzem a possibilidade de amplas mudanças culturais e, quando há espaço para sua ocorrência, resultam em insuficiente flexibilidade para o desenvolvimento de estratégias aceitáveis e adequadas à população local. E, por outro lado, induz à visão equivocada de que as regiões rurais são apenas fonte de matéria-prima e de alimentos, sem considerar as potencialidades e as restrições em relação ao uso do solo e dos recursos naturais disponíveis, despercebe-se das consequências para o meio ambiente e para a sustentabilidade do sistema produtivo e do próprio ambiente que impacta no desenvolvimento regional e nos índices do IDHM.

O segundo caminho, que de forma alguma suprime o primeiro, relaciona-se mais especificamente com o entendimento das relações antrópicas com o meio ambiente nos dias atuais, e a percepção de que precisamos agir considerando as condições anteriormente elencadas, mas também os debates e estudos em nível internacional que apresentam e prospectam resultados, estratégias e prejuízos futuros.

É neste sentido, e também analisando os aspectos históricos e culturais, que o desenvolvimento dos territórios (rurais, urbanos), deve-se ter o cuidado de acompanhar e conhecer os princípios geradores do conceito de sustentabilidade que surgiram a partir da Conferência das Nações Unidas sobre o Meio Ambiente Humano em Estocolmo, no ano de 1972 (CNUMAH,1972). Nesta conferência, debateu-se a importância da geração do desenvolvimento, desde que, sejam mantidas e asseguradas as condições do planeta Terra, centradas em conseguir renovar os recursos naturais, essenciais para a manutenção de toda forma de vida existente na atualidade e no futuro. Ainda, quanto ao uso de recursos naturais não renováveis, estes deverão ser compartilhados sem ser, no entanto, exauridos. Assim, a própria poluição que vir a ocorrer em dependência de algum fator de desenvolvimento não poderá ultrapassar níveis que possam impedir a capacidade natural de recomposição ambiental.

Ao observar nos municípios da região abordada, apontados no estudo de Pietrobelli et. al (2018), os dados apontam para a lógica inversa aos preceitos acima levantados. Visto que a falta de planejamento, os aspectos culturais e a pressão por uma expansão da produção apenas alicerçada no processo capitalista, o lucro pelo lucro, leva ao modelo de produção que não avalia a capacidade do meio ambiente em se regenerar e nem os prováveis danos que podem estar ocasionando à própria espécie humana. 
Por outro lado, se a lógica for invertida e os princípios definidos na Conferência de Estocolmo forem seguidos e tomados como base para a geração do desenvolvimento, esse estaria alicerçado no uso responsável do conhecimento para avaliar as ações de causa e efeito no ambiente natural, mesmo antes da ocorrência das ações antrópicas. Para tanto, destacamse os princípios 2,4 e 17, sendo esses:

- Os recursos naturais da terra incluídos o ar, a água, a terra, a flora e a fauna e especialmente amostras representativas dos ecossistemas naturais devem ser preservados em benefício das gerações presentes e futuras, mediante uma cuidadosa planificação ou ordenamento;

- ao planificar o desenvolvimento econômico deve-se atribuir importância à conservação da natureza, incluídas a flora e a fauna silvestres.

- Deve-se confiar às instituições nacionais competentes a tarefa de planejar, administrar ou controlar a utilização dos recursos ambientais dos estados, com o fim de melhorar a qualidade do meio ambiente.

Observa-se a necessidade de novas construções culturais, de novas visões de mundo, amparadas também pela ação institucional do Estado ao ampliar políticas públicas, entre elas, voltadas para os aspectos educativos, gerar e reformular leis e gerir meios capazes de regular o desenvolvimento, de modo a garantir as condições de sustentabilidade e de preservação natural do meio ambiente e do próprio homem. Assim, cumprindo os princípios legais amparados na Constituição Federal de 1988, de obrigatoriedade do Estado em proteger o meio ambiente das ações antrópicas.

Acrescenta-se também, que o estabelecimento de programas de desenvolvimento no setor rural deveria, segundo Brito (2006), estar alinhado com o conceito de corredores ecológicos, os quais propiciariam as devidas adequações dos setores produtivos com os padrões naturais existentes da flora, fauna e compartimentos ambientais como o solo, o ar e a água, uma vez que, a produção agrícola modifica o meio ambiente quer seja através de instrumentos, máquinas e implementos, bem como pelo uso de insumos de produção que promovem impactos ambientais.

Voltando-se para o cenário da região em destaque e à luz das discussões aqui realizadas, nota-se um cenário socioeconômico de produção em que e a perspectiva do desenvolvimento caminha em contraponto ao conceito de desenvolvimento sustentável, pois, segundo as definições da Organização das Nações Unidas (ONU) e através do relatório Nosso Futuro Comum ou como é conhecido, Relatório Brundtland publicado pela Comissão Mundial para o Meio Ambiente e o Desenvolvimento em 1987 (Brundtland, 1987) é aquele que busca suprir as necessidades presentes sem comprometer a capacidade das gerações futuras de atender suas próprias necessidades.

No entanto, conforme descrito por Lago (2006), o conceito atual de desenvolvimento sustentável, definido na Cúpula Mundial em 2002, através da Comissão de Desenvolvimento Sustentável da ONU, envolve uma definição bem mais ampla e concreta do objetivo de desenvolvimento atual, onde o desenvolvimento sustentável procura a melhoria da qualidade de vida de todos os habitantes do mundo sem aumentar o uso de recursos naturais além da capacidade da Terra. Neste sentido, não restam alternativas conceituais para classificar o desenvolvimento da região abordada no contexto atual, a não ser como aquela onde o desenvolvimento sustentável, contemporaneamente não se aplica, mesmo com a existência de orientação legal, pois, privilegia-se a exploração econômica na expansão capitalista.

Justifica-se a afirmação acima, entre outras pontuações, por exemplo, pelas ações antrópicas realizadas nas propriedades da região usadas nas atividades agrícolas e de produção animal em confinamento, principalmente de suínos e aves, as quais geram grandes quantidades de resíduos e dejetos na produção, observadas na pesquisa de Pietrobelli (et. al., 2018) e dispostas neste texto, onde se aponta ações que propiciam a contaminação do solo e das águas, visto que todos os resíduos e dejetos domésticos e agrícolas (vegetal e animal) tendem a escoar ou infiltrar no solo, atingindo tanto o lençol 
freático, quanto, os mananciais que se encontram nos níveis mais baixos, principalmente, em virtude da eliminação da mata ciliar ao longo dos rios e contribuintes.

Esse fato pode ser comprovado quando se observa a turbidez dos rios e contribuintes que formam essa bacia hidrográfica e drenam o território. Nestes, a turbidez apresenta coloração avermelhada, indicativo do transporte de sedimentos em suspensão, resultantes da erosão do solo e, consequente, arraste de partículas para o interior do leito dos rios. Assim, a disponibilidade de água potável torna-se uma fragilidade para a região. Infelizmente, os corpos hídricos são o caminho principal dos despejos dos esgotos dos núcleos urbanos, das indústrias e das agroindústrias locais, recebendo grande aporte de sedimentos (Pietrobelli, et. al., 2018).

As consequências disso, para além do aspecto visual, estão nas características químicas dos sedimentos lançados. Neste aspecto, pode-se destacar a presença significativa dos elementos nitrogenados, entre eles: a amônia, o nitrato e o nitrito que são oriundos da produção agrícola, tanto pelo uso indiscriminado de adubação química como orgânica, sendo essa última proveniente do uso de dejetos de suínos e aves no solo (Rosa et. al., 2018), aliado a outros fatores tais como: tipo de solo, natureza e composição dos resíduos, bem como as condições climáticas que não podem ser desconsideradas e favorecem a contaminação ambiental, por lixiviação ou acúmulo de nutrientes no perfil do solo (Ceretta et. al, 2005), essas práticas resultam em altos índices de elementos nitrogenados nas águas e apontam como imbricações aos altos índices de câncer na região.

No entanto, deve-se ressaltar que esse problema não está limitado às áreas rurais, como pôde ser observado no estudo realizado por Conceição et. al. (2014) que comprovou elevadas concentrações de nitrato $\left(\mathrm{N}^{\left.-\mathrm{NO}_{3}\right)}\right.$ em poços de abastecimento público na área urbana de Marília-SP. Segundo os autores, tais concentrações eram originadas devido às atividades antrópicas oriundas do esgotamento sanitário por lançamento de efluentes, principal fonte de contaminação das águas subterrâneas. De todo modo, há especificidades a se considerar.

Dessa forma, tanto no ambiente urbano como no ambiente rural, o manejo dos efluentes se torna imprescindível. Ainda, ao retornarmos a análise para este último, as práticas agrícolas sem o uso de medidas adequadas de manejo e conservação do solo, têm como efeito em maior escala, principalmente, a erosão do solo que carreia os fertilizantes e os resíduos orgânicos para os cursos de água. A mobilização excessiva do nitrato para os mananciais decorre, geralmente, da quantidade desses íons aplicados ao solo como fertilizantes em concentrações desproporcionais à capacidade de extração pelas plantas nas lavouras (Rosa et. al., 2018).

Neste ponto, torna-se claro que as ações antrópicas, aqui representadas pela produção agrícola e produção de proteína animal realizadas em pequenas propriedades da região norte do estado do RS, em escala de subsistência, mesmo com a finalidade de manter o homem, têm impactos significativos no desenvolvimento sustentável da região e, por sua vez, no meio ambiente, as atividades agrícolas são realizadas de forma exploratória e sem planejamento, o que aparentemente tenderia ser de controle mais fácil, pois, os meios de produção estão restritos a propriedades que possuem áreas, em média, de 20 hectares (Pietrobelli, et. al., 2018).

Não resta dúvida que o modelo de produção agrícola adotado na região norte do estado do RS, como já mencionado e justificado por Aumond (1999), carece de políticas públicas e ações educacionais capazes de qualificar a visão social, cultural e a consciência na produção rural em relação ao uso e à preservação dos recursos naturais e de seu devido aporte legal. Pode-se ainda ressaltar, nesse contexto, a afirmação de Bulzico (2009) que: os governos podem concordar que falar de meio ambiente em pleno século XXI significa tratar de sobrevivência, pois, a humanidade frente ao processo de industrialização, iniciada há mais de 200 anos através da Revolução Industrial na Inglaterra e, seguindo o modelo atual, marcha para a possibilidade de causar o colapso da existência humana pelo não emprego prático do conceito de sustentabilidade e, consequentemente, pelas 
ações antrópicas degradantes do meio ambiente, que tem como justificativa o progresso econômico ilimitado, em detrimento do desenvolvimento sustentável.

No entanto, Pietrobelli, et. al., (2018) alerta sobre outro dificultador dos processos de construção de novas perspectivas e estratégias para com a questão aqui tratada:

"a descontinuidade de políticas públicas que tem levado ao descrédito em planos e projetos governamentais". Aponta que "No histórico dos últimos anos há uma visão de incentivos a projetos com caráter político ou momentâneo, e que após a mudança de governos em todos os níveis, passam a não ser mais prioridade, até mesmo sendo extintos", assim, causando "prejuízos financeiros, pessoais e familiares aos produtores e descrédito nas políticas públicas e em seus governantes".

Em relação à destinação do lixo, Pietrobelli, et. al., (2018) citam, que na maioria dos municípios e propriedades visitadas, tanto o familiar como o gerado nos sistemas produtivos, se dá na própria propriedade por meio da queima e descarte em aterros incipientes, buracos ou valas (Figura 1). Realidades que corroboram com os dados aprestados pelo IBGE (2010) para a variável sanidade e nessa, a coleta de resíduos sólidos, onde, observa-se que, do total de municípios do estado do Rio Grande do Sul, constituído de 496 municípios, somente 79\% destes municípios apresentam algum serviço de manejo de resíduos sólidos.

Figura 1 - Destinos irregulares do lixo em propriedades agrícolas no norte do estado do Rio Grande do Sul; a) lixo sendo queimado; b) lixo depositado em valas (buracos).

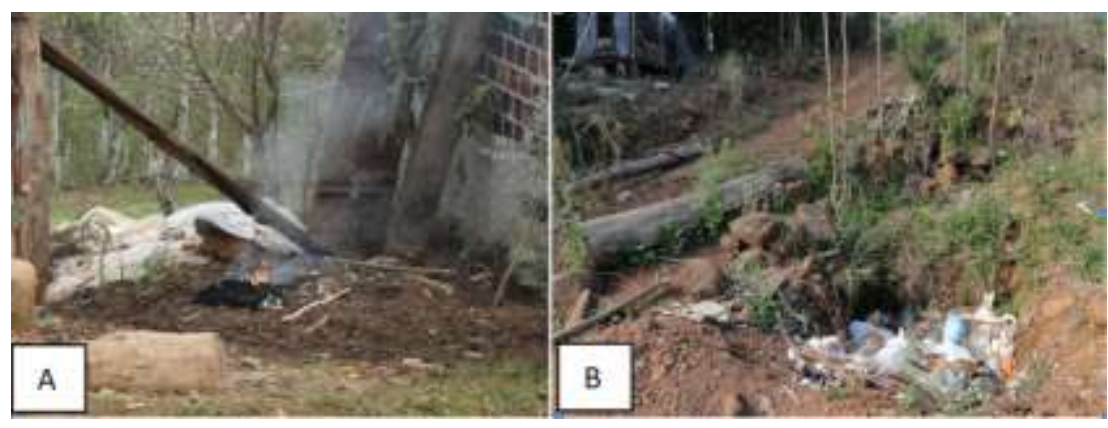

Fonte: Autores.

Neste aspecto, Pietrobelli, et. al., (2018) ressaltam ainda, que observaram outra questão: a falta de adequação no armazenamento de produtos agroquímicos ${ }^{6}$, o descarte de embalagens de produtos agrícolas no campo por parte de alguns produtores rurais e, inclusive, a reutilização de vasilhames de agrotóxicos para outros fins como, por exemplo, na confecção de comedouros para animais de criação, favorecendo uma cadeia de contaminações por agentes químicos amplamente tóxicos nos compartimentos de solo e água.

No entanto, a maioria dos produtores rurais e seus familiares não possuem esse conhecimento legal e, muito menos, prático. Por outro lado, o que se observa é a total desatenção e falta de consciência do prejuízo amplo, com o manuseio e armazenamento desses produtos tóxicos (Figura 2).

\footnotetext{
${ }^{6}$ Sobre os produtos agroquímicos e o destino das embalagens, deve-se destacar que o Decreto número 4.074, de 4 de janeiro de 2002 que regulamentou a Lei número 7.802, de 11 de julho de 1989, dispõe sobre a pesquisa, a experimentação, a produção, a embalagem e rotulagem, o transporte, o armazenamento, a comercialização, a propaganda comercial, a utilização, a importação, a exportação, o destino dos resíduos e embalagens, o registro, a classificação, o controle, a inspeção e a fiscalização de agrotóxicos, seus componentes e afins. A mesma lei estabelece normas para o armazenamento adequado dos produtos agroquímicos, os quais deverão estar "[...] em local com boa ventilação, livre de inundações e distante de residências, de instalações para animais ou de locais onde se armazenam alimentos ou rações". Ainda, "Os produtos devem ser devidamente agrupados em prateleiras, por classe de princípio ativo, nunca devem estar em contato direto com o piso e sempre apresentar os rótulos intactos".
} 
Figura 2. Falta de estrutura adequada para o armazenamento de produtos agroquímicos (tóxicos).

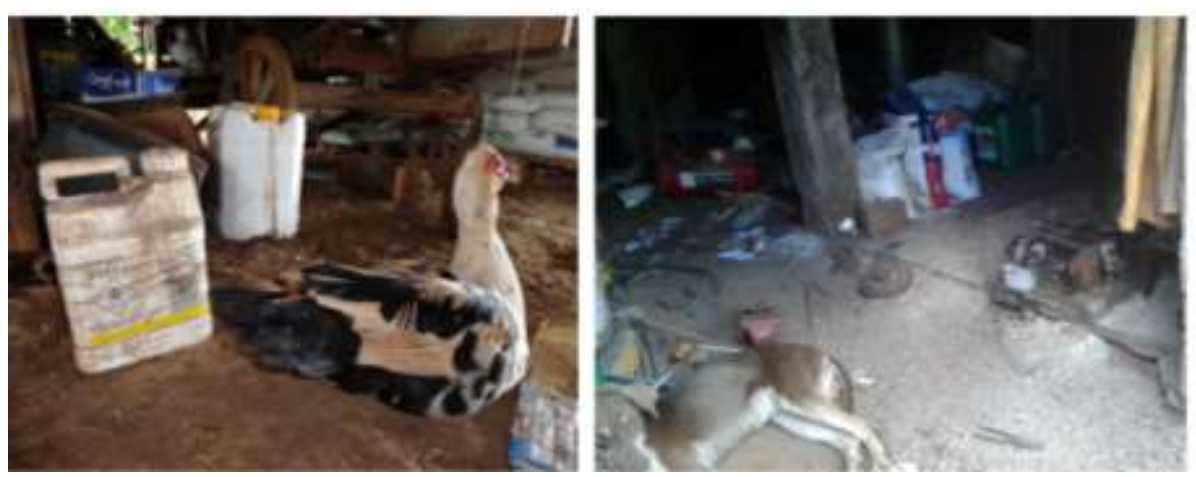

Fonte: Autores.

Conforme Pietrobelli, et. al., (2018), nos municípios em questão, não foi percebido a existência de políticas públicas de logística reversa, conforme a Lei $N^{\circ}$ 12.305/2010 (BRASIL 2010), em relação aos resíduos sólidos e nem mesmo a observância da Lei No 9.974/2000 que determina os destinos de vasilhames dos produtos agrotóxicos para o devido descarte. A partir da não observância prática das orientações legais acima mencionadas, que permitiriam restringir o avanço poluidor dos compartimentos ambientais pelos princípios ativos dos agroquímicos expostos ao meio ambiente, destaca-se o princípio de poluidor-pagador intrínseco à Lei 6.938/81 conforme descrito no Art. 4\%/VII: à imposição, ao poluidor, e ao predador, da obrigação de recuperar e/ou indenizar os danos causados e, ao usuário, da contribuição pela utilização de recursos ambientais com fins econômicos.

Contudo, deve-se ter o entendimento adequado desse princípio poluidor-pagador, o qual, não libera a poluição ambiental mediante pagamentos, mas, que procura estabelecer um princípio educador aos exploradores de recursos naturais de maneira equilibrada, integrando às ações antrópicas de produção, geradoras de valor econômico em benefício familiar/social, sem gerar danos impactantes ao meio ambiente.

Não obstante, um programa governamental de educação ambiental direcionado aos produtores rurais também deveria destacar a Lei número 12.305/2010, que prevê ao recebedor de resíduos sólidos contaminantes e, por extensão, bem como aqueles que protegem o meio ambiente natural em benefício da comunidade, o recebimento de uma compensação financeira pelas ações de preservação do bem natural (Camerini, 2009).

De modo geral, existe uma consciência ainda pouco consistente de que o uso incorreto dos agrotóxicos podem causar prejuízos à saúde humana e ao meio ambiente. Conforme, Pietrobelli, et. al., (2018), os autores não constataram nas propriedades rurais, a existência de práticas que consolidem uma consciência ambiental nos produtores rurais e nos seus familiares. Os autores afirmam ainda que faltam cursos de capacitação para o manejo dos produtos agroquímicos, seu armazenamento e que enfatizem a necessidade da utilização de Equipamentos de Proteção Individual (EPIs).

Agregando-se à discussão deste tema, citamos também a Lei número 9.605/1998, a Lei dos Crimes Ambientais (Brasil, 1998), dispondo sobre sanções penais e administrativas de modo sistematizado e tipificado acerca das condutas lesivas ao meio ambiente. Contudo, retorna-se ao ponto fundamental deste artigo, a carência de sistemática educação ambiental, e de fontes de capacitação para os produtores rurais, pois, constatou-se que muitos desconhecem tanto os aspectos legais que o amparam no uso e conservação dos recursos naturais, assim como, desconhecem os dispostos na Lei dos Crimes Ambientais com possíveis punições.

Neste cenário, fica evidente que as políticas públicas, principalmente aquelas que tratam da educação ambiental, não estão efetivamente presentes no meio da produção rural e no meio educacional, tanto do ponto de vista da ação, quanto, da aplicação da lei explicitada no Art. 225 da Constituição Federal que no $§ 1^{\circ}$ responsabiliza o poder público a tomar medidas 
que viabilizem sua execução; isso está claro no parágrafo VI, onde se lê que ao poder público compete: promover a educação ambiental em todos os níveis de ensino e a conscientização pública para a preservação do meio ambiente. Não se trata apenas de aplicar a lei, mas, também de conscientização e para conscientizar é sabido que há necessidade de educar, construir conhecimento e consciência, sendo essa, possibilidade a partir da educação formal e da educação ambiental, em princípios de construção cultural.

A Lei n ${ }^{\circ}$ 9.795/99 de 27 de abril de 1999 (Brasil, 1999) que dispõe sobre a educação ambiental e institui a Política Nacional de Educação Ambiental, afirma que a educação ambiental inclui os processos por meio dos quais o indivíduo e a coletividade constroem valores sociais, conhecimentos, habilidades, atitudes e competências voltadas para a conservação do meio ambiente, bem de uso comum do povo, essencial à sadia qualidade de vida e sua sustentabilidade. No seu artigo $2^{\circ}$, afirma ainda, que é um componente essencial e permanente da educação nacional, devendo estar presente em todos os níveis e modalidades do processo educativo. Nesse contexto, destaca-se ainda o artigo $4^{\circ}$, no qual são definidos os princípios básicos da educação ambiental e onde se lê acerca da concepção do meio ambiente em sua totalidade, considerando a interdependência entre o meio natural, o sócio-econômico e o cultural, sob o enfoque da sustentabilidade.

Não obstante, cabe-nos ressaltar ainda outro enfoque ambiental diante da falta de conhecimento por parte do produtor rural, bem como, da própria falta de aplicação dos princípios legais em programas governamentais, municipais, escolares, comunitários e acadêmicos, de modo a educar as pessoas do setor produtivo primário: trata-se do valor do meio ambiente. Que valor se deve dar a uma fonte de água que abastecerá uma propriedade rural, alimentará uma família, abastecerá uma lavoura ou horta, podendo servir para dessedentação animal? E qual será o valor de um dano se essa mesma fonte for contaminada por produtos agroquímicos, devido à falta de conhecimento específico por parte do produtor rural para o manejo adequado de produtos tóxicos (agroquímicos)?

Dentre as atitudes e estratégias possíveis para iniciar novas atitudes, pode-se iniciar a tomada de ações embasadas em exemplos que já são efetivos. Dentre eles, o entendimento de que a educação é uma das melhores maneiras para despertar valores éticos ambientais nas sociedades e, além disso, o entendimento de que somos parte de um todo e que este todo não está aí apenas para nos servir (Reigota, 2017), e mais ainda, que não é inesgotável, nos responsabiliza a medir nossas ações e suas consequências. No entanto, isso só pode ser possível se houver consciência ambiental como construção cultural coletiva, como parte de nossos processos educativos e de humanização.

Ainda que o direito ao desenvolvimento atribua aos Estados à liberdade de explorar seus recursos naturais (Aleixo \& Bastos, 2017), nossa atitude exploratória e predatória resulta em armadilhas que estamos preparando para contrapor a finalidade básica dos genes que carregamos, e, assim, estamos infligindo a nós mesmos ao negligenciar dos transtornos ao meio ambiente por ações antrópicas que não atentam ao conceito de sustentabilidade, e podem estar causando, em última análise, violações aos direitos humanos. Pois, como visto anteriormente, o desenvolvimento sustentável deve procurar a melhoria da qualidade de vida e, por outro lado, dispor dos recursos ambientais sem que seu uso esteja além da capacidade da Terra (CMDS, 2002).

Por mais que as questões ambientais passem a fazer parte dos problemas da humanidade, o seu tratamento se torna de difícil compreensão para a população em geral, tendo como um dos agravantes, o perfil de educação formal pelo qual somos perpassados. Este perfil, segundo Valeirão e Oliveira (2013), contempla a disciplinarização, ou seja, o tratar do tema de forma compartimentalizada, o que, segundo os autores, é apontado como uma das maiores causas da falta de compreensão das questões ambientais. Esta lógica estimulou o desenvolvimento tecnológico sem a devida preocupação com o meio ambiente, na sua forma holística de ser.

Ao rever essa forma equivocada de entender as relações antrópicas com o ambiente, bem como, a inter-relação dos campos das ciências e suas articulações que compreendem tanto processos práticos e de estudos do ambiente e suas relações 
evolutivas de uma forma fragmentada, voltar-se-ia para uma compreensão de forma mais abrangente, complexa e dialógica, chegando-se a interdisciplinaridade. Esta, conforme Leff (2008), propiciaria uma conexão com os diversos campos do conhecimento, independente da disciplina, protagonizando o entendimento das implicações das ações de forma ampla e de uma melhor compreensão sobre o ambiente.

Assim, em última análise, este conhecimento para a construção de novas perspectivas culturais deve representar uma realidade histórico-social, plurifacetada e com visão interdisciplinar (Coimbra, 2000), reavendo a conjunção e intersecção complexa da vida e dos recursos naturais. É neste sentido, que campos de estudo como as Ciências Ambientais se voltam para a interdisciplinaridade com o objetivo de reunir as ciências sociais com as ciências naturais, tecnológicas e exatas propondo diretamente melhorar a sociedade (Drummond \& Schroeder, 1998).

A partir destas compreensões, entende-se que a consciência ambiental se constrói de maneira gradual, perpassada por ações constantes em educação interdisciplinar e ambiental. Então, as ações antrópicas, antes de serem efetivadas, passam primeiramente a ser analisadas considerando conceitos como o de sustentabilidade, tornando práticas as construções presentes no subconsciente dos atores sociais e qualificando para o atendimento a orientação legal voltada ao direito ao meio ambiente na Constituição Federal de 1988, conforme o Art. 225, onde consta que "Todos têm direito ao meio ambiente ecologicamente equilibrado, bem de uso comum do povo e essencial à sadia qualidade de vida, impondo-se ao Poder Público e à coletividade o dever de defendê-lo e preservá-lo para presentes e futuras gerações".

\section{Considerações Finais}

É importante conhecer e refletir sobre os aspectos e processos históricos e culturais que caracterizam uma região (rural, urbana), também, aspectos sociais e econômicos envolvidos na definição do perfil de exploração e de interferência antrópica no meio ambiente, as quais possibilitam melhores condições de análise sobre atitudes tomadas no passado, bem como as atitudes no presente e as necessidades que nos cobram atitudes a serem tomadas em relação aos objetivos ligados à preservação e ao uso sustentável dos recursos naturais. Tudo isso, não esta a parte dos processos culturais que caracterizam perfis regionais e constituem suas vocações. Ao analisar a região norte do estado do RS, destacou-se que o perfil perseguido pelo projeto histórico de colonização da região, interfere diretamente na maneira como a ação antrópica e o uso dos recursos naturais passa a ocorrer.

A partir do estudo, compreende-se que há urgência em repensar estas questões evidenciadas na referida região, em atitudes em que a sustentabilidade deve ser buscada através do cumprimento da legislação existente e de suas necessárias reformulações, do envolvimento de toda a sociedade, quer seja na conservação, preservação, na recuperação e na melhoria do meio ambiente, bem como, deve estar presente nos processos educativos para a educação ambiental - incluindo-se tais assuntos na grade curricular do ensino fundamental, médio, técnico e superior e na perspectiva interdisciplinar, visto que os recursos ambientais são de uso de todos (direta ou indiretamente), de modo que a sustentabilidade adquira um valor ético cultural e de responsabilidade de toda a sociedade (produtora/consumidora).

Para tanto, afirma-se ser necessário criar e manter programas educacionais de pesquisa, extensão e projetos contínuos para que as sociedades consigam se desenvolver a compreensão da capacidade finita do meio ambiente e, quando possível, atuar para sua regeneração, com atenção permanente à formação de valores, competências, atitudes e habilidades que não inviabilizem a ação antrópica em sua relação com o meio ambiente, mas, que propiciem a atuação individual e coletiva voltada para a prevenção, a identificação e a solução de problemas ambientais, para ser alcançada a essência do princípio de sustentabilidade não pela força de lei, mas pelo padrão de consciência coletiva. Claro, sem desconsiderar as particularidades locais e regionais. 


\section{Referências}

Aleixo, L. S. P. \& Bastos, S. P. (2017). Direito ao meio ambiente: um direito humano. Direitos humanos e meio ambiente. Fortaleza: Expressão, $133-151$.

Aumond, J. J. (1999). Desenvolvimento sustentável: realidade ou utopia? Revista de Estudos Ambientais. FURB / IPA, 1, 5-11.

Avelar, B. C. M. \& Paschoal, S. R. R. I. (2012). Política Ambiental Municipal: importância do Plano Diretor em normatizar a ocupação e expansão urbana no que tange ao desenvolvimento sustentável e recuperação ambiental. In: Revista Âmbito Júridico. Direito Ambiental.

Bauman, Z. (2012). Ensaios sobre o conceito de cultura. Zahar, 328p.

Brasil, Governo Federal. (1998). Lei N ${ }^{\circ}$ 12.305, de 2 de agosto de 2010. Institui a Política Nacional de Resíduos Sólidos, altera a Lei no 9.605 , de 12 de fevereiro de 1998.

Brasil, Governo Federal. (1999). Lei de educação ambiental no 9.795/99.

Brasil. (1988). Constituição Federal. Constituição da República Federativa do Brasil. Senado Federal: Centro Gráfico, 296p.

Brasil. (2001). Estatuto da Cidade: Lei $n^{\circ}$ 10.257. Brasília: Câmara dos Deputados, Coordenação de Publicações, 273 p.

Brasil. (2011) Governo Federal. Lei $n^{\circ}$ 9.605, de 12 de fevereiro de 1998. Dispõe sobre as sanções penais e administrativas derivadas de condutas e atividades lesivas ao meio ambiente.

Brasil. (2011). Governo Federal. Lei $n^{o}$ 6.938, de 31 de agosto de 1981. Dispõe sobre a Política Nacional do Meio Ambiente, seus fins e mecanismos de formulação e aplicação.

Brito, F. (2006). Corredores Ecológicos: uma estratégia integradora na gestão de ecossistemas. UFSC.

Brundtland, G. H. (Org.). (1987). Nosso futuro comum. FGV.

Bulzico, B. A. A. (2009). O direito fundamental ao meio ambiente ecologicamente equilibrado: origens, definições e reflexos na ordem constitucional brasileira. 236 fl. Dissertação (Mestrado em Direitos Fundamentais e Democracia). Faculdades Integradas do Brasil, Curitiba.

Camerini, J. C. B. (2009). Os instrumentos jurídico-econômicos e a construção do desenvolvimento sustentável. Uma reflexão sobre o ICMS ecológico. Jus Navigandi, Teresina, ano 14, n. 2330.

Ceretta, C. A., Basso, C. J., Pavinato, P. S., Trentin, E. E. \& Girotto, E. (2005). Produtividade de grãos de milho, produção de matéria seca e acúmulo de nitrogênio, fósforo e potássio na rotação aveia preta/milho/nabo forrageiro com aplicação de dejeto líquido de suínos. Ciência Rural, 35, $1287-1295$.

Cmds, C. M. S. D. S. (2002). Plano de Implementação de Johanesburgo. Organização das Nações Unidas. Johanesburgo.

CNUMAH. (1972). Declaração de Estocolmo sobre o ambiente humano. Estocolmo.

Coimbra, J. de Á. A. (2000). Considerações sobre a interdisciplinaridade. Interdisciplinaridade em ciências ambientais, p. 52-70.

Conceição, F. T. D., Mazzini, F., Moruzzi, R. B. \& Navarro, G. R. B. (2014). Influências naturais e antrópicas na qualidade da água subterrânea de poços de abastecimento público na área urbana de Marília (SP). Revista Brasileira de Recursos Hídricos, 19(3), 227-238.

Drummond, J. A. \& Schroeder, A. (1998). Programas de Pós-Graduação em Ciências Ambientais e similares no Brasil - uma listagem preliminar. Rev. Ambiente \& Sociedade. NEPAM, $\mathrm{n}^{\circ} .2, \mathrm{p} .139$.

Embrapa. (2013). Centro Nacional de Pesquisas de Solos. Sistema Brasileiro de Classificação de Solos. Embrapa Solos. 353p.

Geraldino, C. F. G. (2014). Uma definição de meio ambiente. GEOUSP - Espaço e Tempo (Online), 18, 403-415.

Gil, A. C. (2008). Métodos e técnicas de pesquisa social. (6a ed.), Editora, Atlas SA.

Gould, S. J. (2006). Darwin e os grandes enigmas da vida. Martins Fontes.

Hartshorne, R. (1978). Propósitos e natureza da geografia. (2a ed.), Trad. Thomaz N. Neto. Hucitec.

IBGE. (2010). Censo demográfico. http://www. ibge. gov. br.

Junges, J. R. (2004). Ética Ambiental. UNISINOS.

Lago, A. A. C. (2007). Estocolmo, Rio, Joanesburgo: o Brasil e a três conferências ambientais das Nações Unidas. Thesaurus Editora.

Leff, E. (2001). Saber ambiental: sustentabilidade, racionalidade, complexidade, poder. (2a ed.), Vozes/PNUMA. 343p.

Lewontin, R. (1998). A tripla hélice. Companhia das Letras.

Mattos, P. \& Rodrigues, R. G. (2010). O desenvolvimento do diagnóstico estratégico em propriedades rurais do agronegócio: análise ambiental em uma propriedade rural familiar.

Mesquita, A. P. \& Ferreira, W. R. (2017). O Município e o planejamento rural: o plano diretor municipal como instrumento de ordenamento das áreas rurais. Espaço em Revista, 18(1). 
Research, Society and Development, v. 10, n. 10, e463101019245, 2021

(CC BY 4.0) | ISSN 2525-3409 | DOI: http://dx.doi.org/10.33448/rsd-v10i10.19245

Minayo, M. C. S. (2002). Pesquisa Social. Teoria, método e criatividade. (21a ed.), Vozes. 80p.

Peloggia, A. U. G. (1997). Delineação e Aprofundamento temático da Geologia do Tecnógeno do Município de São Paulo (As consequências geológicas da ação do homem sobre a natureza e as determinações geológicas da ação humana em suas particularidades referentes à precária ocupação urbana). São Paulo, 262p. (Tese de Doutoramento, Instituto de Geociências da Universidade de São Paulo).

Pietroblli, A. C., Sorgato, A. C., Targino, A. P., Storck, A., Mendonça, A. M., Wastowski, A. D., Nery, B. J., Rosa, G. M., Garlet, G., Costa Junior, J. A., Silva, J. C., Stumm, J. O, Rosa, J. S. M., Oliveira, L. P., Silva, L., Sippert, L. R., Munaretto, L. F., Natalli, L. E., Gabriel, M., Golombieski, R. M., Schneider, S. I., Barros, S. \& Storck, T. R. (2018). Desenvolvimento Sustentável Regional, fortalecimento de cadeias produtivas da agricultura familiar. Grafimax, 1. 282p.

Reigota, M. (2017). O que é educação ambiental. Brasiliense.

Rosa, G. M. D., Gabriel, M., da Silva, J. C., Mendonça, A. M., Junior, J. A. C., \& Wastowski, A. D. (2018). Leaching of the different forms of nitrogen by the application of poultry litter, swine waste, and mineral nitrogen on corn cultures (Zea mays L.). Environmental quality management, $28(1)$, 131-138.

Rüsen, J. (2014). Cultura Faz Sentido: orientações entre o ontem e o amanhã. Editora Vozes.

Rüsen, J. (2015). Teoria da História: Uma teoria da história como ciência. Editora UFPR.

Silva, F. R. (2014). A Constituição dos Processos Educacionais: História da Educação em Frederico Westphalen/RS (1917 - 1950). 197 f. Dissertação (Mestrado em Educação) - Universidade Federal de Santa Maria.

Silva, F. R. (2019). Associações polonesas União das Sociedades Kultura e Oswiata (Curitiba - PR) - antagonismos e polonidade(s) na diáspora (18901939). 407 f. Tese (Doutorado em História) - Universidade Federal de Santa Maria.

Valeirão, K., \& Oliveira, A. R. (2013). Governamentalidade e práxis educacional na contemporaneidade. Educação e Filosofia, Uberlândia, $27,559-578$. 